\title{
Expression of Plasminogen Activator Inhibitor-1 by Olfactory Ensheathing Glia Promotes Axonal Regeneration
}

\author{
DIANA SIMÓN ${ }^{1}{ }^{1}$ MARIA JESÚS MARTÍN-BERMEJO ${ }^{1}$ MARIA TERESA GALLEGO-HERNÁNDEZ,${ }^{1}$ \\ ÉRIKA PASTRANA, ${ }^{2}$ VEGA GARCÍA-ESCUDERO, ${ }^{1,3}$ ANA GARCÍA-GÓMEZ, ${ }^{1}$ FILIP LIM, ${ }^{3,4}$ \\ JAVIER DÍAZ-NIDO, ${ }^{1,4}$ JESÚS ÁVILA, ${ }^{1,5, *}$ AND MARIA TERESA MORENO-FLORES ${ }^{1 *}$ \\ ${ }^{1}$ Centro de Biología Molecular "Severo Ochoa" (C.S.I.C.-U.A.M.), Universidad Autónoma de Madrid, Spain \\ ${ }^{2}$ Nature Publishing Group, New York \\ ${ }^{3}$ Departamento de Biología Molecular, Universidad Autónoma de Madrid, Spain \\ ${ }^{4}$ CIBERER, Centro de Investigación Biomédica en Red de Enfermedades Raras, Spain \\ ${ }^{5}$ CIBERNED, Centro de Investigación Biomédica en Red de Enfermedades Neurodegenerativas, Spain
}

\section{KEY WORDS}

adult axonal repair; plasminogen activator inhibitor-1 (PAI1); proteinase-activated receptor-1 (PAR-1); thrombomodulin; retinal ganglion neurons (RGCs)

\begin{abstract}
Olfactory ensheathing glia (OEG) cells are known to facilitate repair following axotomy of adult neurons, although the molecular mechanisms involved are not fully understood. We previously identified plasminogen activator inhibitor-1 (PAI-1), proteinase-activated receptor-1 (PAR-1), and thrombomodulin (TM) as candidates to regulate rat OEGdependent axonal regeneration. In this study, we have validated the involvement of these proteins in promoting axonal regeneration by immortalized human OEGs. We studied the effect of silencing these proteins in OEGs on their capacity to promote the regeneration of severed adult retinal ganglion cells (RGCs) axons. Our results support the role of glial PAI-1 as a downstream effector of PAR-1 in promoting axon regeneration. In contrast, we found that TM inhibits OEG induced-axonal regeneration. We also assessed the signaling pathways downstream of PAR-1 that might modulate PAI-1 expression, observing that specifically inhibiting $\mathrm{G}_{\mathrm{i}}$, Rho kinase, or PLC and PKC downregulated the expression of PAI-1 in OEGs, with a concomitant reduction in OEG-dependent axon regeneration in adult RGCs. Our findings support an important role for the thrombin system in regulating adult axonal regeneration by OEGs. @ 2011 Wiley-Liss, Inc.
\end{abstract}

\section{INTRODUCTION}

Central nervous system (CNS) axons fail to regrow and re-establish connections after damage (Ramón y Cajal, 1928). Thus, creating an appropriate environment for axonal regeneration is fundamental to achieve functional repair after injury in the CNS. Cell therapy based studies suggest that olfactory ensheathing glia (OEG) can induce axonal regeneration after CNS injury (Barnett and Riddell, 2007; Moreno-Flores and Avila, 2006; Moreno-Flores et al., 2002; Raisman and Li, 2007; Richter and Roskams, 2008; Thuret et al., 2006). Indeed, OEGs promoted CNS axonal regeneration, as corroborated by different in vitro and in vivo studies (Chuah et al., 2004; Imaizumi et al., 1998; Li et al., 1997; Ramer et al., 2004; Ramon-Cueto et al., 2000; Sasaki et al., 2006; Sonigra et al., 1999).

Previously, we established immortalized OEG clonal cell lines conserving the proregenerative capacity of primary OEGs with promise for their therapeutic use (Garcia-Escudero et al., 2010, 2011; Lim et al., 2010; Moreno-Flores et al., 2003a,b, 2006). The mechanisms by which OEGs facilitate axonal outgrowth are still not fully understood. To elucidate them, we used microarrays to compare the gene expression profiles of OEG populations with different regenerative capacity, thus identifying several molecules that can regulate axonal regeneration (Pastrana et al., 2006, 2007), three of which were related to the thrombin signaling system: proteinase-activated receptor-1 (PAR-1) and the plasminogen activator inhibitor-1 (PAI-1) were upregulated in regenerative OEG populations and thrombomodulin (TM) in the nonregenerative OEG population. Thrombin signals through PAR-1, and TM is an allosteric modulator of thrombin that attenuates this signaling. In addition, it has been shown in several cell systems that thrombin regulates the expression of PAI-1 (Dichek and Quertermous, 1989; Hackett and Campochiaro, 1993; Hayakawa et al., 1995; Noda-Heiny et al., 1993). Moreover, inhibitors of plasminogen activators, including PAI-1, have been implicated in neurite outgrowth (Leprince et al., 1991; Pittman et al., 1989; Sumi et al., 1992). For these reasons, we have studied the role of these proteins in OEG-dependent axonal regeneration in more detail. Specifically, we have examined the activity

Additional Supporting Information may be found in the online version of this article.

Grant sponsors: Noscira, The Fundación M. Botín, The Spanish "Plan Nacional", Fundación Ramón Areces, CIBERNED, Spanish Ministry and C.S.I.C.

*Correspondence to: M. Teresa Moreno-Flores or Jesús Ávila, Centro de Biología Molecular "Severo Ochoa" (C.S.I.C.-U.A.M.), Facultad de Ciencias, Universidad Autónoma de Madrid, 28049 Madrid, Spain. E-mail: mtmoreno@cbm.uam.es or javila@cbm.uam.es

Received 2 December 2010; Accepted 27 April 2011

DOI 10.1002/glia.21189

Published online 27 May 2011 in Wiley Online Library (wileyonlinelibrary.com). 
of PAR-1 and PAI-1 in promoting OEG-dependent axonal regeneration and that of TM in hindering this process.

PAR-1 is a G-protein-coupled receptor mainly activated by thrombin and other serine proteinases-proteolytic cleavage (Vu et al., 1991; Wang et al., 2006). PAR-1 may couple to different G proteins (Hung et al., 1992; Offermanns et al., 1994), mediating diverse activities. In addition, different effects of its activator thrombin on astrocytes and neurons have been reported in vitro (Cavanaugh et al., 1990; Grabham and Cunningham, 1995; Perraud et al., 1987; Pindon et al., 1998; Suidan et al., 1997; Vaughan et al., 1995).

PAI-1 belongs to the serpin family of serine protease inhibitors, regulating the activity of the tissue-type plasminogen activator (t-PA) and urokinase-type plasminogen activator (u-PA) (Vassalli et al., 1991). The association of protease activity with the regulation of neurite outgrowth (Diaz-Nido et al., 1991; Monard et al., 1983; Pittman et al., 1989; Zurn et al., 1988) supports a role for the PA/PAI-1 system in neuritogenesis (Leprince et al., 1991; Pittman et al., 1989; Sumi et al., 1992).

TM, an integral membrane chondroitin sulfate proteoglycan, complexes with thrombin and inhibits its activity (Esmon, 1987). TM appears to be active in the human and murine CNS (Pindon et al., 1997; Wong et al., 1991).

Here, we found that activation of PAR- 1 and of its downstream effector, PAI-1, contributes to OEG-induced axonal regeneration of adult CNS neurons. In contrast, TM is a negative modulator of axonal regeneration.

\section{MATERIALS AND METHODS Reagents}

The following reagents were purchased from the indicated suppliers: Thrombin and PAI-1 (Calbiochem, Germany), Y27632 (Sigma, St. Louis, MO), U0126 (Promega, Madison, WI), SCH-79797, Pertussis toxin (PTX), U73122, and GF109203X (Tocris Bioscience, Bristol, United Kingdom).

\section{Immortalization of Primary Human OEG Cultures}

Human olfactory bulb tissue was obtained from the Tissue Bank for Neurological Research (Madrid, Spain): tissue was donated and extracted according to the Bank's approved legal and ethical protocols. Primary cultures of OEG were prepared from human olfactory bulbs derived from young and elderly cadaver donors as described (Garcia-Escudero et al., 2010; Lim et al., 2010) and employing a method described previously with modifications (Moreno-Flores et al., 2003a,b). The cultures established in this way contained $>99 \%$ cells that expressed the $\mathrm{S} 100 \beta$ protein and diffuse glial fibrillary acidic protein (GFAP) (Lim et al., 2010 ), detected by antibodies against $\mathrm{S} 100 \beta$ (Sigma) and GFAP (Chemicon International, Temecula, CA).

Immortalized OEG clonal lines were established by transfer of the combination of lentivectors encoding
BMI1 and TERT into the human OEG primary cultures (Lim et al., 2010). In the case of elderly donor cultures, we established clonal lines, hTL, which were then maintained in ME medium: DMEM-F12 supplemented with $10 \%$ fetal calf serum (Hyclone, Logan, UT), $20 \mu \mathrm{g} / \mathrm{mL}$ pituitary extract (Gibco, Carlsbad, CA), and $2 \mu \mathrm{M}$ forskolin (Alomone Labs, Jerusalem, Israel). We selected the hTL4 line as a representative neuroregenerative human OEG cell population (Fig. 1a) (Lim et al., 2010).

\section{Co-cultures of Postmitotic RGCs with Primary and Immortalized OEG}

Extension of neurites by postmitotic retinal ganglion cells (RGCs) was used as a model of regeneration in culture (Moreno-Flores et al., 2003a,b; Sonigra et al., 1999; Wigley and Berry, 1988). Briefly, retinal tissue was extracted from adult 2-month-old rats and digested with papain $(20 \mathrm{U} / \mathrm{mL}$ papain; Worthington, Lakewood, NJ) in the presence of $50 \mu \mathrm{M}$ of the NMDA receptor inhibitor, D,L-2-amino-5-phosphonovaleric acid (Sigma). The mixed retinal cell suspension was then plated on either $10 \mu \mathrm{g} /$ $\mathrm{mL}$ poly-L-lysine (PLL)-treated coverslips or on human OEGs monolayers (Moreno-Flores et al., 2003b). The cultures were maintained at $37^{\circ} \mathrm{C}$ with $5 \% \mathrm{CO}_{2}$ for $96 \mathrm{~h}$ in serum-free Neurobasal medium (Invitrogen, Carlsbad, CA) supplemented with B-27 (Invitrogen) and $25 \mathrm{mM}$ $\mathrm{KCl}$ (NB-B27), before they were fixed with $4 \%$ paraformaldehyde (PFA) in phosphate-buffered saline (PBS).

All inhibitors, PTX (100 ng/mL), Y27632 (10 $\mu \mathrm{M})$, U73122 $(10 \mu \mathrm{M})$, GF109203X $(10 \mu \mathrm{M})$, or U0126 (10 $\mu \mathrm{M}$ ), were added to the human OEG layers $24 \mathrm{~h}$ prior to plating of the neurons on the monolayer. This was done to measure their effect on PAR-1 cascades in the OEG and not in the neurons. Therefore, all inhibitors were present on the OEG only prior to co-culture with neurons and washed out upon medium change to NB-B27 when RGCs were added to the system.

PAI-1 neutralizing antibody (MA- 33B8 from Calbiochem; $\alpha$-PAI-1; $10 \mu \mathrm{g} / \mathrm{mL}$ ) or control mouse nonimmune IgG (Santa Cruz Biotechnology, Santa Cruz, CA; $10 \mu \mathrm{g} /$ $\mathrm{mL}$ ) was added to the co-culture at the time of plating neurons and maintained for $96 \mathrm{~h}$.

In all experiments, we confirmed viability of the OEG monolayer before plating RGCs onto the glial cells.

\section{Conditioned Media}

NB-B27 was added to shPAI-1 1 or control ShRNA hTL4 cells, and after 4 days, the medium was collected and centrifugated for debris and cells removing. Conditioned media were added to the RGCs plated on PLL and maintained for $96 \mathrm{~h}$.

\section{ShRNAs Lentiviral Transduction}

ShRNAs lentiviral transduction to silence the corresponding genes was carried out prior to the plating of 
a

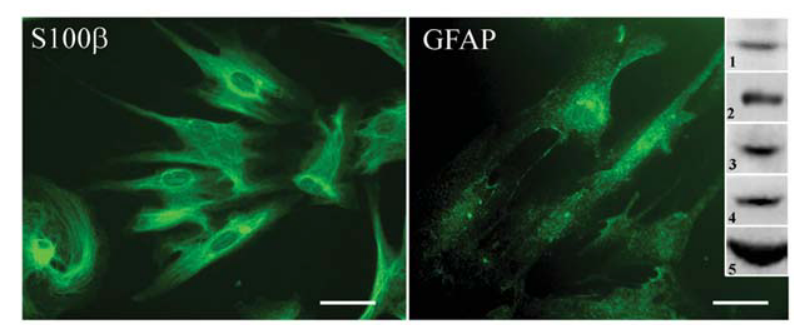

b
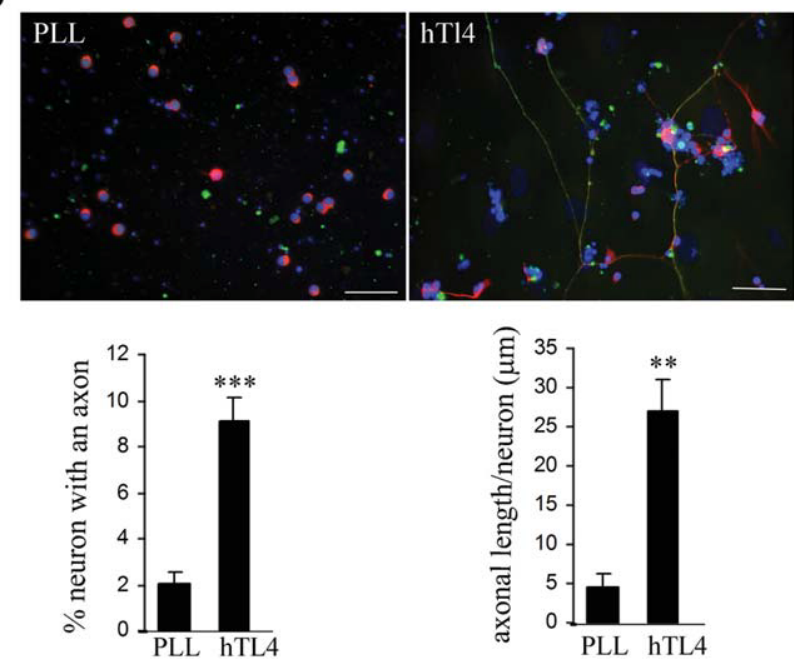

C

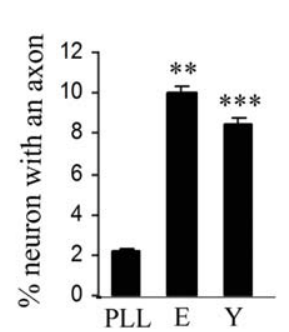

Fig. 1. hTL4 and primary human OEG cells stimulate adult axonal regeneration. (a) Expression of the OEG markers S100 $\beta$ and GFAP in the hTL4 cell line was analyzed by immunocytochemistry. Scale bars, $20 \mu \mathrm{m}$. The expression of thrombin, PAR-1, PAI-1, and TM in hTL4 cells was confirmed by Western blot. (Inset 1 to 4 , respectively; 5 : $\beta$ actin, loading control). (b) Retinal ganglion cells (RGCs) of adult rats (60 days) were plated onto poly-L-lysine (PLL) or onto hTL4-OEG, and after $96 \mathrm{~h}$, the neurons with an axon were quantified (phosphorylated MAP1B positive neurites, green label) with respect to the total number of alive neurons (MAP2 antibody labeled, red) as well as the mean axonal length per neuron [axonal length/neuron $(\mu \mathrm{m})$ ] defined as total axonal length (micrometers) in 20 fields divided by the total number of counted neurons. Nuclei were stained with DAPI (blue). Scale bars, 40 $\mu \mathrm{m}$. (c) Histograms represent axonal regeneration levels exhibited by RGCs plated onto PLL or onto primary human culture OEGs derived from elderly (E) and young (Y) human donors. Data represent the mean \pm SEM of 5 (b) or 3 (c) independent experiments. Asterisks indicate significant difference $(*: P<0.05$; **: $P<0.01$; ***: $P<0.005$, Student's $t$ test).

the RGC. Briefly, hTL4 cells or primary OEG cells were seeded in ME for $24 \mathrm{~h}$, and subsequently, lentiviral shRNA particles specific to each protein or nontargeted unspecific shRNA (control; Mission ${ }^{\text {TM }}$, Sigma) were added to the cells in DMEM at a multiplicity of infection
(MOI) of 2. The medium was replaced with ME $16 \mathrm{~h}$ after infection, and after 3 days, immediately before the addition of retinal neurons, the medium was changed to NB-B27. After $96 \mathrm{~h}$, the co-culture was fixed with $4 \%$ PFA for analysis by immunofluorescence. An additional control was included to confirm that no residual infectious lentivector remained at the time of neurons were plated. For this, hTL4 were infected with a GFP expressing-lentivector and after $16 \mathrm{~h}$ medium was replaced with fresh ME. After 3 days, the medium was changed to NB-B27 before plating retinal neurons and after $96 \mathrm{~h}$ co-cultures were fixed and we performed immunostaining for 514 antibody to identify neurons. As we show in Supp. Info. Fig. 1a, neurons did not exhibit green staining (GFP), indicating there was no residual virus that could be infecting neurons.

In parallel, infected OEGs were maintained under the same conditions as co-cultures for subsequent Western blot analysis. The silencing of the genes was verified at the moment of neurons plating and at the end of the experiment ( $96 \mathrm{~h}$ of co-culture; Supp. Info. Fig. 1b).

\section{Neuronal Markers in RGC-Glial Co-cultures}

The SMI-31 monoclonal antibody (Sternberger and Sternberger, 1983) was purchased from Sternberger Monoclonal (Baltimore, MD), and it was used as an axonal marker as it detects mode I-phosphorylated epitopes on microtubule-associated protein-1B (MAP-1B) and high molecular weight (HMW) neurofilament subunit (NF-H) proteins (Ulloa et al., 1993a). Microtubule-associated protein 2 (MAP2), a marker of the somatodendritic compartment, was detected using the 514 rabbit polyclonal antiserum, which recognizes HMW MAP2 isoforms (MAP2A and B), irrespective of their phosphorylation state (Sanchez Martin et al., 1998).

\section{Quantification of Axonal Regeneration}

Preparations were quantified by observers blinded to sample identity by counting axons under the $40 \times$ objective of an inverted Axiovert200 microscope (Zeiss, Oberkochen, Germany). A minimum of 20 randomly chosen fields were quantified for each treatment, and each experiment was repeated a minimum of three times. Axonal regeneration was quantified as the percentage of neurons with an axon, identified by SMI-31 staining, whereas the total number of neurons was determined by staining with the antibody 514 against MAP2 in 20 $40 \times$-fields (at least 200 neurons were counted). Axons were defined as polarized neurites stained with the SMI-31 antibody. We also determined the mean axonal length per neuron. This parameter was determined using the NeuronJ plugin (E. Meijering) of the ImageJ software (Wayne Rasband, National Institutes of Health, Bethesda, MD). This parameter is defined as the sum of the lengths (in micrometers) of all axons identified divided by the total number of counted neurons, independently of 
that they presented axon or not. All measurements were derived from quantification of a minimum of 20 fields photographed at $40 \times$ magnification. The number of neurons per $40 \times$-field was not significantly different across treatments.

\section{Immunocytochemistry}

Immunocytochemistry was performed as described previously (Salinero et al., 1997). Briefly, cells fixed with $4 \%$ PFA were washed and preincubated with PBS containing $0.1 \%$ Triton $\mathrm{X}-100$ and $1 \%$ serum (PBS-TS). The primary SMI-31 (1/500) 514 (1/400), GFAP (1/1,000, from Promega), and S100 $\beta$ (1/500, from Sigma) antibodies were diluted in PBS-TS and incubated overnight with cells. After washing, the samples were incubated with Alexa-488 and -594 (Molecular Probes, Eugene, OR) fluorescent secondary antibody conjugates. Nuclei were stained with $10 \mu \mathrm{g} / \mathrm{mL}$ DAPI for $10 \mathrm{~min}$. Then the samples were washed and immediately mounted with Fluoromount-G (Southern Biotech., Birmingham, AL).

\section{Western Blotting}

Protein extracts for Western blot analysis were prepared from subconfluent hTL4 cultures seeded in 60-mm plates with the indicated treatments. Total protein extracts were prepared from the cultures by scraping the dishes in $20 \mathrm{mM}$ HEPES ( $\mathrm{pH} 7.4$ ), $100 \mathrm{mM} \mathrm{NaCl}$, $100 \mathrm{mM} \mathrm{NaF}, 1 \mathrm{mM} \mathrm{Na} \mathrm{VO}_{4}, 5 \mathrm{mM}$ EDTA, and $1 \%$ Triton $\mathrm{X}-100$. After maintaining the samples for $15 \mathrm{~min}$ on ice, a small aliquot was withdrawn for protein determination by the Bradford method, while SDS sample buffer was added to the remainder, and the extracts were boiled and frozen. The same amount of protein of each sample was resolved by SDS-PAGE (Laemmli, 1970) on $8 \%$ or $10 \%$ polyacrylamide gels and then electrotransfered to a nitrocellulose filter. The filters were blocked with $10 \%$ nonfat milk in PBS, $0.2 \%$ Tween-20, and then incubated with the primary antibodies at the following dilutions: anti-PAR-1 (1/500, Santa Cruz Biotechnology, Santa Cruz, CA), anti-PAI-1 (1/1,000, Abcam, Cambridge, United Kingdom), anti-TM (1/1,000, Santa Cruz Biotechnology), anti-thrombin (1/1,000, Abcam), using anti- $\beta$-actin or anti- $\beta$-tubulin to control for protein loading control (Sigma, 1/1,000). After washing, the filters were incubated with the corresponding peroxidaseconjugated secondary antibody, and the labeling was visualized by ECL (Amersham, Freiburg, Germany). Band intensities were measured using Quantity One densitometry software (Bio-Rad, Munich, Germany) and normalized to the $\beta$-tubulin or $\beta$-actin signal.

\section{RESULTS \\ Axonal Regeneration Is Promoted by the Human Immortalized OEG Cell Line, hTL4}

We previously generated hTL4 cells, a human immortalized OEG cell line ( $\mathrm{Lim}$ et al., 2010), which can be identified with GFAP and $\mathrm{S} 100 \beta$ as markers (Fig. 1a).We tested the capacity of the hTL4 OEG line to promote axonal regeneration in vitro (Fig. 1b) using a coculture system (Moreno-Flores et al., 2003b; Sonigra et al., 1999; Wigley and Berry, 1988). In these co-cultures, adult rat RGCs were obtained from dissociated and digested retinas, a process in which all of the neurons lose their axons providing us with a model of axon regeneration in culture. Axonal regeneration of RGCs was quantified after $96 \mathrm{~h}$ in culture onto poly-L-lysine (PLL) or onto a hTL4 monolayer by immunostaining with SMI31 antibody, an axonal marker as it detects mode I-phosphorylated epitopes on microtubule-associated protein-1B (MAP-1B) (Ulloa et al., 1993b) and HMW neurofilament subunit (NF-H) proteins, and with 514 antibody, a somatodendritic compartment marker as it recognizes HMW microtubule-associated protein 2 (MAP2) isoforms (MAP2A and B). Then, the percentage of neurons with axons and the mean axonal length per neuron was determined (Fig. 1b). In contrast to PLL, hTL4 cells were capable of promoting adult axonal regeneration (Fig. 1b) to levels similar to that observed using primary cultured OEGs derived from elderly and young human donors (Fig. 1c) and other human OEG lines that also exhibit this proregenerative capacity (Garcia-Escudero et al., 2011; Lim et al., 2010).

In a previous study, we found that the expression of the $P A R-1$ and $P A I-1$ genes increased in the populations that favored axon regeneration and that TM expression augmented in the nonregenerative population (Pastrana et al., 2006). These three proteins are all related to the thrombin signaling system, and hence, we decided to validate their function in our model of adult CNS axon regeneration using co-culture of RGCs with the hTL4 human OEG line. Our first step was to confirm that hTL4 cells express these three proteins and thrombin, which was verified by Western blot (Fig. 1a inset).

\section{PAR-1 Is Implicated in the Stimulation of Adult Axonal Regeneration by Human OEG}

To examine the possible role of PAR-1 in the axonal regeneration promoted by hTL 4 cells, we silenced PAR-1 expression using two specific shRNA (1 and 2, in Fig. 2a). The hTL4 OEG cells were infected with a lentivector that expressed a shRNA directed against PAR-1 (shPAR-1 1 and 2) $72 \mathrm{~h}$ before plating the RGC, and the co-cultures were then maintained for 96 additional hours before they were fixed and analyzed. We quantified the proportion of neurons with an axon and the mean axonal length per neuron, comparing hTL4 treated with shPAR-1 versus those infected with a nontarget shRNA lentivector (control, C). After $72 \mathrm{~h}$ of lentivector shPAR-1 infection, there was a clear $49 \%$ and $53 \%$ reduction in PAR-1 expression (Fig. 2b) with shPAR-1 1 and 2, respectively, and this decrease was maintained throughout the co-culture time (Supp. Info. Fig. 1b). This reduction in PAR-1 paralleled the $\sim 50 \%-$ $60 \%$ decrease in the number of neurons bearing an axon 
a

PAR-1 CDNA

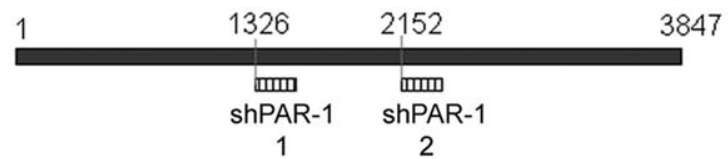

b

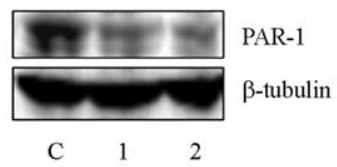

C

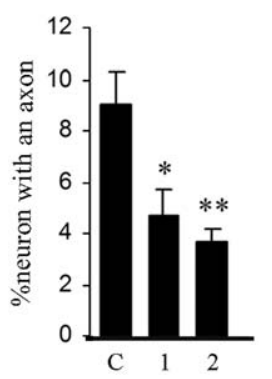

d
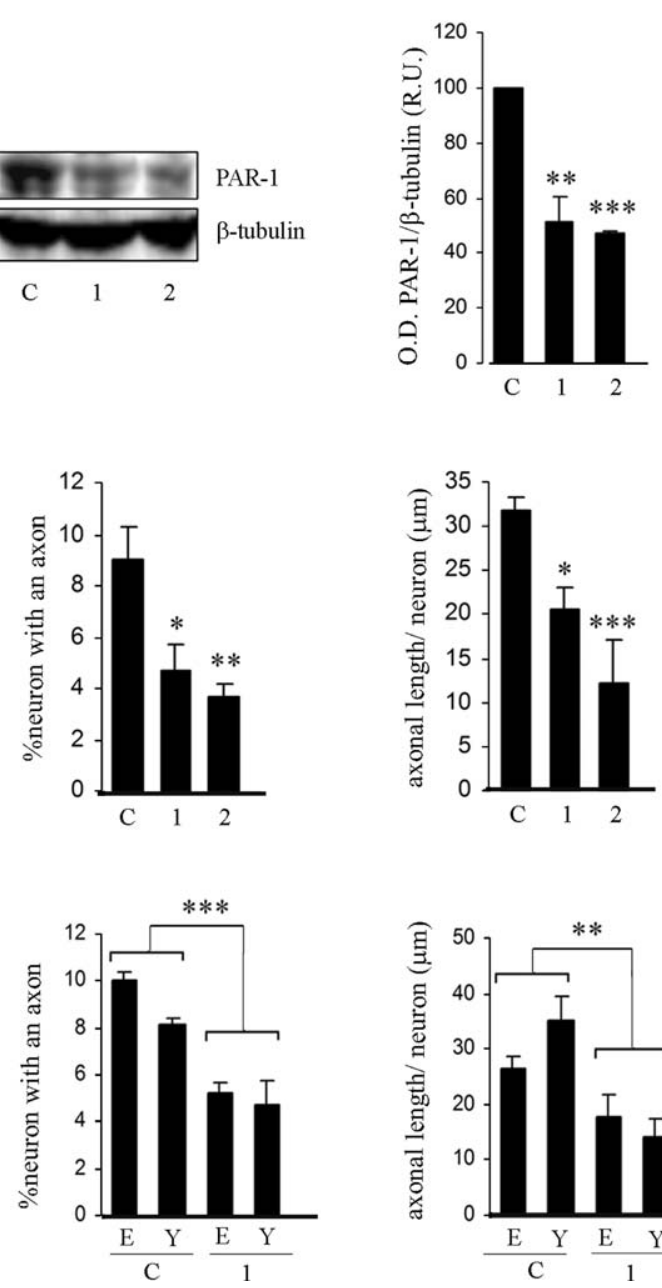

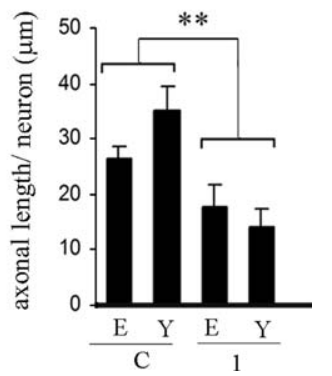

Fig. 2. PAR-1 is involved in supporting axonal regeneration by human OEG cells. hTL4-OEG cells were transduced with shPAR-1 (shPAR-1 1 and 2 in scheme a), and PAR-1 expression was analyzed in Western blots (b). The levels of $\beta$-tubulin were used as a control of the amount of protein. The optical densities (O.D.) of protein bands were determined by densitometry and are expressed as ratios of the band densities of control cells, defined as 100 relative units (R.U.). (c) Percentage of neurons with an axon and the mean axonal length per neuron ([axonal length/neuron $(\mu \mathrm{m})]$ defined as in Fig. 1) in co-cultures on shPAR-1 (1 or 2) or shRNA-control (C) lentivirus transduced hTL4 cells. Data are mean \pm SEM (bars) values of at least three assays $(n=3$ with shPAR-1 1 and $n=4$ with shPAR-1 2). (*: $P<0.05$; **: $P<0.01$; ***: $P<0.005$, Student's $t$ test). (d) The Percentage of neurons with an axon and the mean axonal length per neuron ([axonal length/neuron $(\mu \mathrm{m})$ ] defined as in Fig. 1) were measured in co-cultures on primary human culture OEGs (phOEG) derived from elderly (E) and young (Y) human donors that were transduced with shPAR-1 (1) or shRNA-control (C) lentivirus. The histograms show the mean \pm SEM values from two independent assays. ANOVA analysis was carried out, $P \leq 0.001$ and $P \leq 0.005$ for both dependent variables "percentage of neurons with an axon" and "mean axonal length per neuron," respectively. Then post hoc multiple comparisons between means were performed: *** $P \leq$ 0.001 and $* * P=0.005$ Tukey test (for comparison phOEG/shRNA-control vs. phOEG/shPAR-1). after infection with either shPAR-1 1 or 2 and with a $35 \%$ and $62 \%$ reduction in mean axonal length per neuron, respectively (Fig. 2c). Number of neurons per $40 \times-$ field was not modified by any of the treatments, meaning that we did not detect changes in adhesion and or survival of plated RGCs (data not shown).

Similar results were observed using primary cultures OEG derived from young and elderly human donors, in which PAR-1 silencing caused a decrease in the axonal regeneration of the RGC that were co-cultured with these cells (Fig. 2d).

\section{PAI-1 Favors Axonal Regeneration Promoted by Human OEG}

To corroborate the function of PAI-1 in axonal regeneration mediated by hTL4-OEGs, we again used two different lentivectors that expressed an shRNA that targeted this molecule (shPAI-1 1 and shPAI-1 2 in Fig. 3a). The hTL4 cells were transduced with shPAI-1 (1 and 2) $72 \mathrm{~h}$ before plating the RGC, and after $96 \mathrm{~h}$ of co-culture, we evaluated the proportion of neurons with an axon and the mean axonal length per neuron when PAI1 was silenced in hTL4 cells (Fig. 3c). In parallel in these cells, we verified that there was a $70 \%$ and $54 \%$ reduction in PAI-1 expression with shPAI-1 1 and 2, respectively, at the moment of platting neurons (Fig. $3 \mathrm{~b}$ ), and this silencing was maintained until the end of the experiment (Supp. Info. Fig. 1b). These PAI-1 silenced-hTL4 cells promoted less axon regeneration in adult RGC than control hTL4. Indeed, there was a $65 \%$ and $53 \%$ decrease in the number of neurons with an axon with shPAI-1 1 and 2, respectively, and similarly, $60 \%$ and $40 \%$ shorter axons were detected following transduction with these shRNAs (Fig. 3c). This effect was also observed in co-cultures with primary OEG derived from young and elderly human donors (Fig. 3d). Therefore, silencing PAI-1 in these cells produced a reduction in the axonal regeneration of the RGCs.

To test whether the effect of PAI-1 on axonal regeneration was due to its functions as a OEG-secreted factor, we analyzed how the conditioned media derived from control-hTL4 or from PAI-1 silenced-hTL4 affected to the axonal regeneration of adult RGCs plated on PLL. The axonal regeneration of RGCs incubated with control-hTL4 conditioned medium was substantially increased compared with that of RGCs maintained in fresh medium, especially as reflected by their long axons. In contrast, conditioned media derived from PAI1 silenced-hTL4 promoted less axonal regeneration of RGCs than control-hTL4 conditioned media, suggesting that PAI-1 contributes to axonal regeneration by acting as a soluble factor released by OEGs (Fig. 4a).

To further demonstrate the role of PAI-1 as an OEGsecreted factor that facilitates axonal regeneration, a neutralizing antibody of PAI-1 was added to the co-cultures of RGCs on primary OEGs, showing that this reduced the percentage of neurons with an axon and the mean axonal length per neuron. No changes in axonal 
a

PAI-1 cDNA

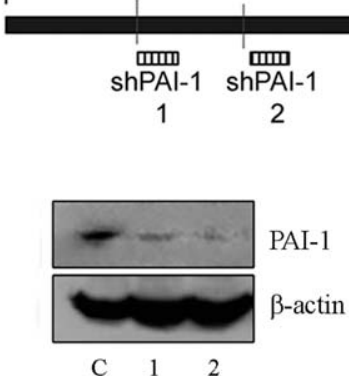

C

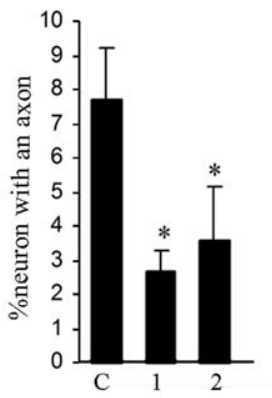

d

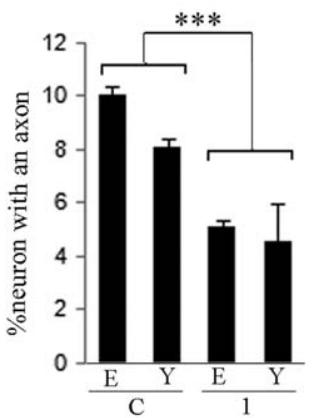

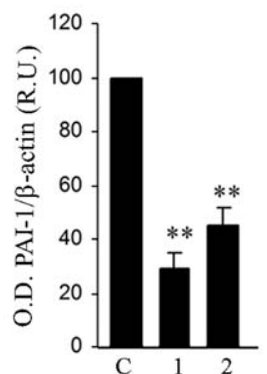
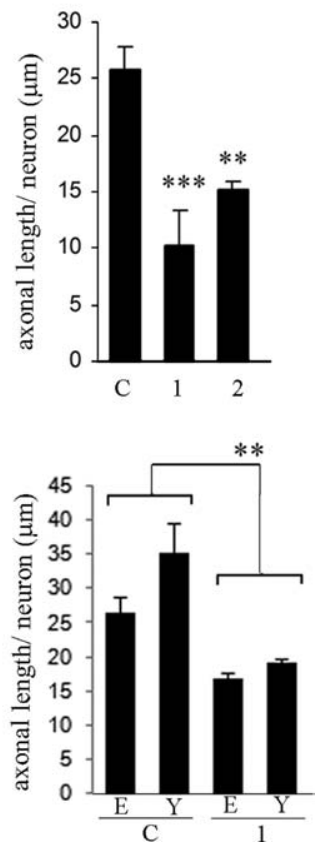

Fig. 3. PAI-1 is an inducer of adult axonal regeneration by OEG cells. Knockdown of PAI-1 expression by shPAI-1 (sequence 1 and 2 in scheme a) in hTL4 cells was determined in Western blots using a specific antibody against PAI-1. (b) An antibody against $\beta$-actin was used as a loading control. Densitometric analyses were performed by combining the results of three independent assays, densities were normalized with respect to loaded protein, and data were expressed as percentages of control values (100\%, R.U.). (c) Axonal regeneration was evaluated by quantifying the average number of neurons with an axon and the mean axonal length per neuron ([axonal length/neuron $(\mu \mathrm{m})]$ defined as in Fig. 1) in co-cultures with hTL4 transduced with shPAI-1 (1 and 2) or sh-RNA-control (C) lentivirus. The data are the mean of three independent experiments \pm SEM (bars). Asterisks indicate significant difference $(*: P<0.05$; **: $P<0.01$; ***: $P<0.005$, Student's $t$ test). (d) RGC were plated on co-cultures on primary human OEGs (phOEG) derived from elderly $(\mathrm{E})$ and young $(\mathrm{Y})$ human donors that were transduced with shPAI-1 (1) or shRNA-control (C) lentivirus and the percentage of neurons with an axon and the mean axonal length per neuron [axonal length/neuron $(\mu \mathrm{m})$ ] were measured. The histograms represent the mean \pm SEM values from two independent assays. ANOVA analysis was carried out: $P<0.001$ and $P<0.005$ for both dependent variables "percentage of neurons with an axon" and "mean axonal length per neuron," respectively. Then post hoc multiple comparisons between means were performed: $* * * P \leq 0.001$ and $* * P=0.01$ Tukey test (for comparison phOEG/shRNA-control vs. phOEG/shPAI-1). a
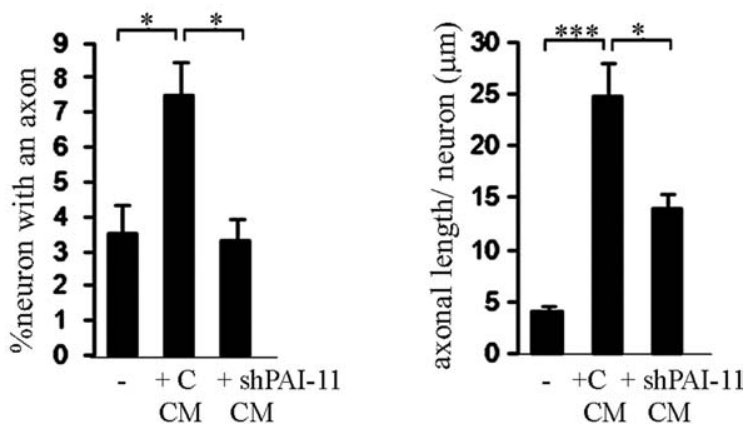

b
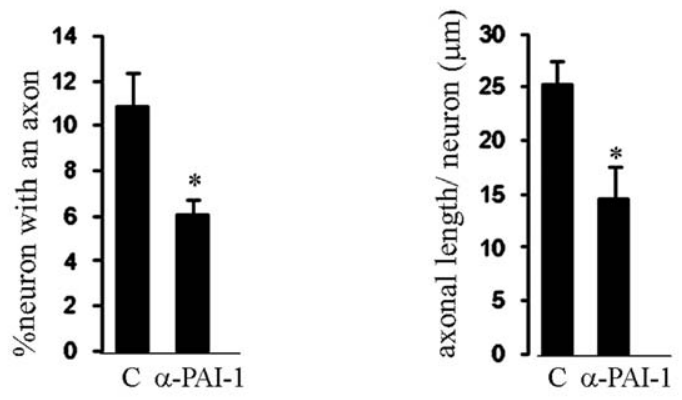

C
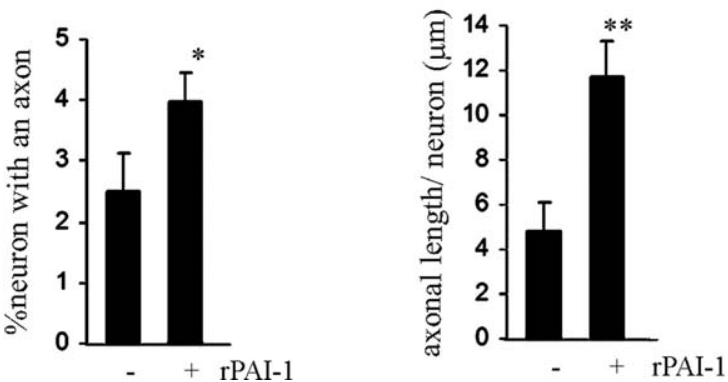

Fig. 4. PAI-1 acts as a secreted factor in OEGs-mediated axonal regeneration. (a) RGCs were plated on PLL and maintained on fresh medium (-), on conditioned medium (CM) of control hTL4 (control shRNA, C CM), or on conditioned medium of PAI-1-silencing hTL4 (shPAI-1 $1 \mathrm{CM}$ ) for $96 \mathrm{~h}$, after which the percentage of neurons with an axon and the mean axonal length per neuron [axonal length/neuron $(\mu \mathrm{m})]$ were quantified. The graphs represent the mean $\pm \mathrm{SEM}$ values from three independent assays. ANOVA analysis was carried out: $P=$ 0.022 and $P=0.001$ for both dependent variables "percentage of neurons with an axon" and "mean axonal length per neuron," respectively. Then post hoc multiple comparisons between means were performed: *** $P=0.001, * * P<0.01$ and $* P<0.05$ Tukey test [for comparisons PLL (-) vs. PLL+control CM (C CM) and PLL+ control CM (C CM) vs. PLL+shPAI-1 1 CM]. (b) Quantification of axonal regeneration of RGCs co-cultured on primary OEGs in the presence of PAI-1 neutralizing antibody $(\alpha-$ PAI- 1$)$ or mouse IgG $(C)$. The data show the mean \pm SEM values from three independent assays. (*: $P<0.05$, Student's $t$ test statistical analysis). (c) Axotomized adult RGCs were plated on PLL coated cover-slips in the presence or absence of recombinant PAI-1 (10 $\mathrm{ng} / \mathrm{mL})$. After $96 \mathrm{~h}$ in culture, the percentage of neurons with an axon and the mean axonal length per neuron $(\mu \mathrm{m})$ were quantified. The histograms show the mean \pm SEM values from six independent assays. $(*$. $P<0.05$, Student's $t$ test statistical analysis).

regeneration were observed when control IgG antibody was added (Fig. 4b).

Additionally, we decided to test the effect of the addition of recombinant PAI-1 to RGCs cultured on PLL, and as expected, we observed that this protein produced an 
a

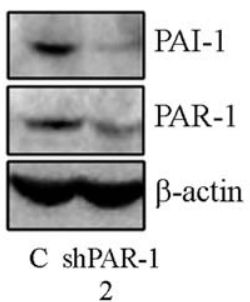

C

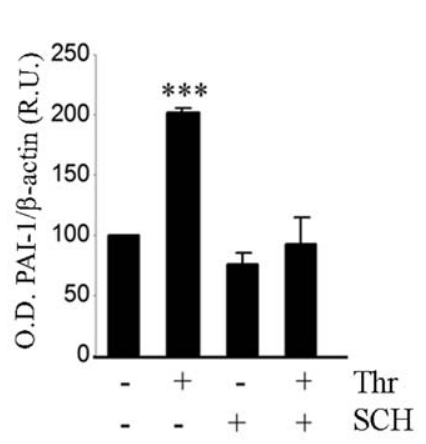

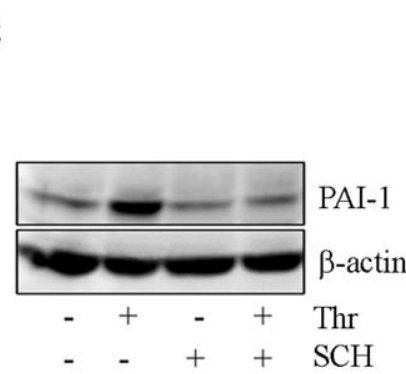

b
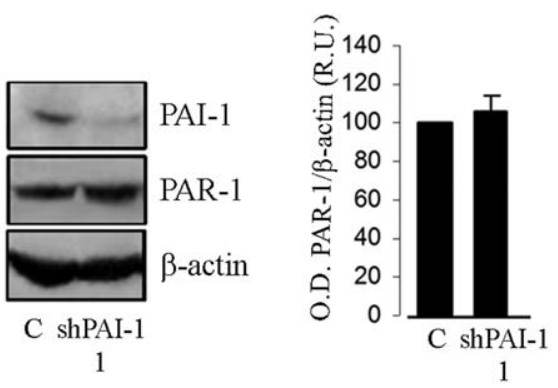

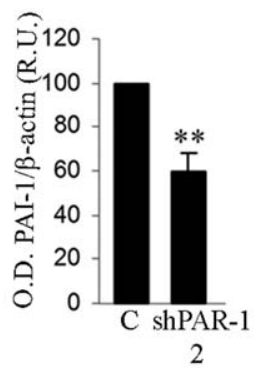

d
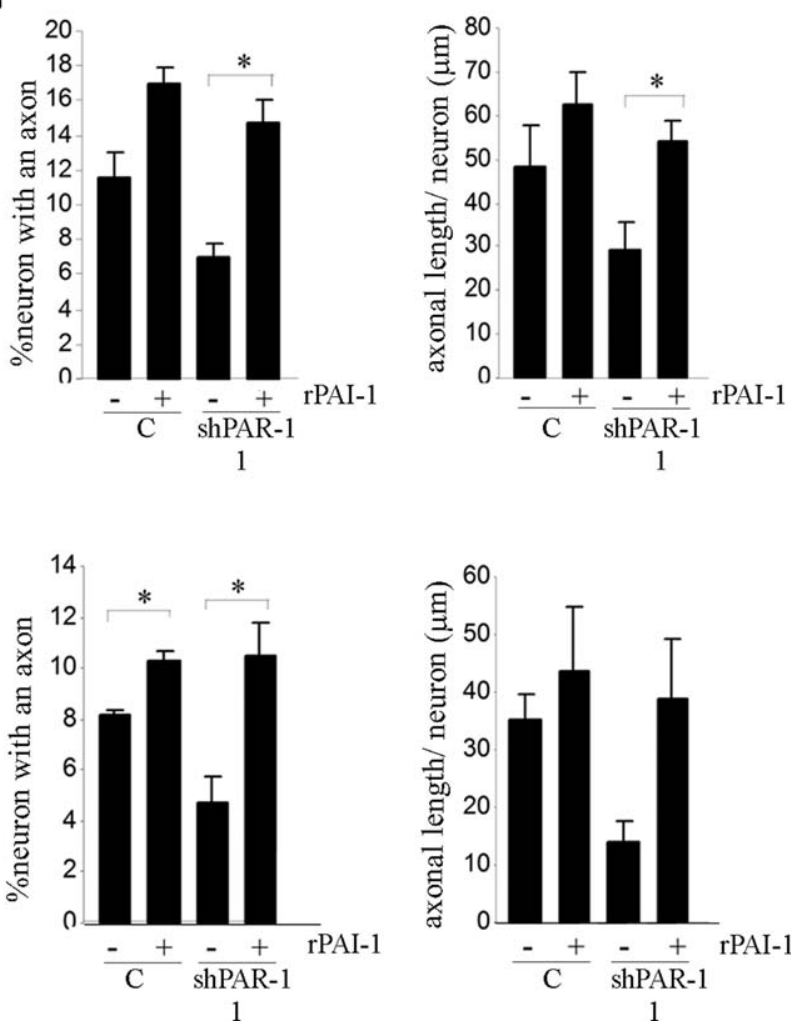

Fig. 5. PAI-1 expression was reduced in PAR-1-silenced hTL4 cells. Analysis of PAI-1 and PAR-1 expression in Western blots of both PAI-1(a) and PAR-1- (b) silenced hTL4 cells using monoclonal antibodies against these proteins. An antibody against $\beta$-actin was employed as a loading control. (c) hTL4 cells were treated with thrombin (50 nM), SCH-79797, or both for $24 \mathrm{~h}$, and lysates were immunoblotted and probed for PAI-1. Protein loading was verified by $\beta$-actin staining. Histograms represent densitometric quantification of PAI-1 and PAR-1 immunoreactivity normalized to the $\beta$-actin antibody signal ( $a, b$, and $c)$. Data are referred to values of mean \pm SEM of at least three different assays (*: $P<0.05$; **: $P<0.01$; ***: $P<0.005$, Student's $t$ test).

increase in axonal regeneration determined by the two parameters analyzed: percentage of neurons with an axon and the mean axonal length per neuron (Fig. 4c).

\section{PAI-1 Lies Downstream of the Thrombin PAR-1 Receptor in Human OEG}

To study the relationship between PAR-1 and PAI-1 in the process of axon regeneration, we used shRNA-PAR-1
Thrombin-treated hTL4-OEGs exhibited more PAI-1 than untreated cells. This elevation of PAI-1 expression induced by thrombin was abrogated when SCH-79797 was added to cells. (d) RGCs were plated on PAR-1-silenced (shPAR-1 1) or on control (C) hTL4 and human primary OEG cells (upper and lower histograms, respectively) in the presence or absence of PAI-1 (10 ng/mL) and assessed for axonal regeneration at 96 $\mathrm{h}$. The percentage of neurons with an axon and the mean axonal length per neuron ([axonal length/neuron $(\mu \mathrm{m})]$ defined as in Fig. 1) were determined. Values shown are the mean $\pm \operatorname{SEM}(n=3$ and $n=2$ for experiments with hTL4 and primary OEG, respectively). (*: $P<0.05$; **: $P<0.01$; ***: $P<0.005$, Student's $t$ test).

(shPAR-1 2) and shRNA-PAI-1 (shPAI-1 1) lentivector infection to silence the expression of these genes in hTL4 cells. The silencing of PAR-1 produced a concomitant downregulation of PAI-1 7 days after infection (Fig. 5a). However, silencing PAI-1 with the corresponding shRNA did not affect the expression of PAR-1 (Fig. 4b), suggesting that PAI-1 expression lies downstream of PAR-1. Furthermore, PAI- 1 expression was augmented 2-fold by 24 -h exposure of hTL4 cells to thrombin, the main agonist for 


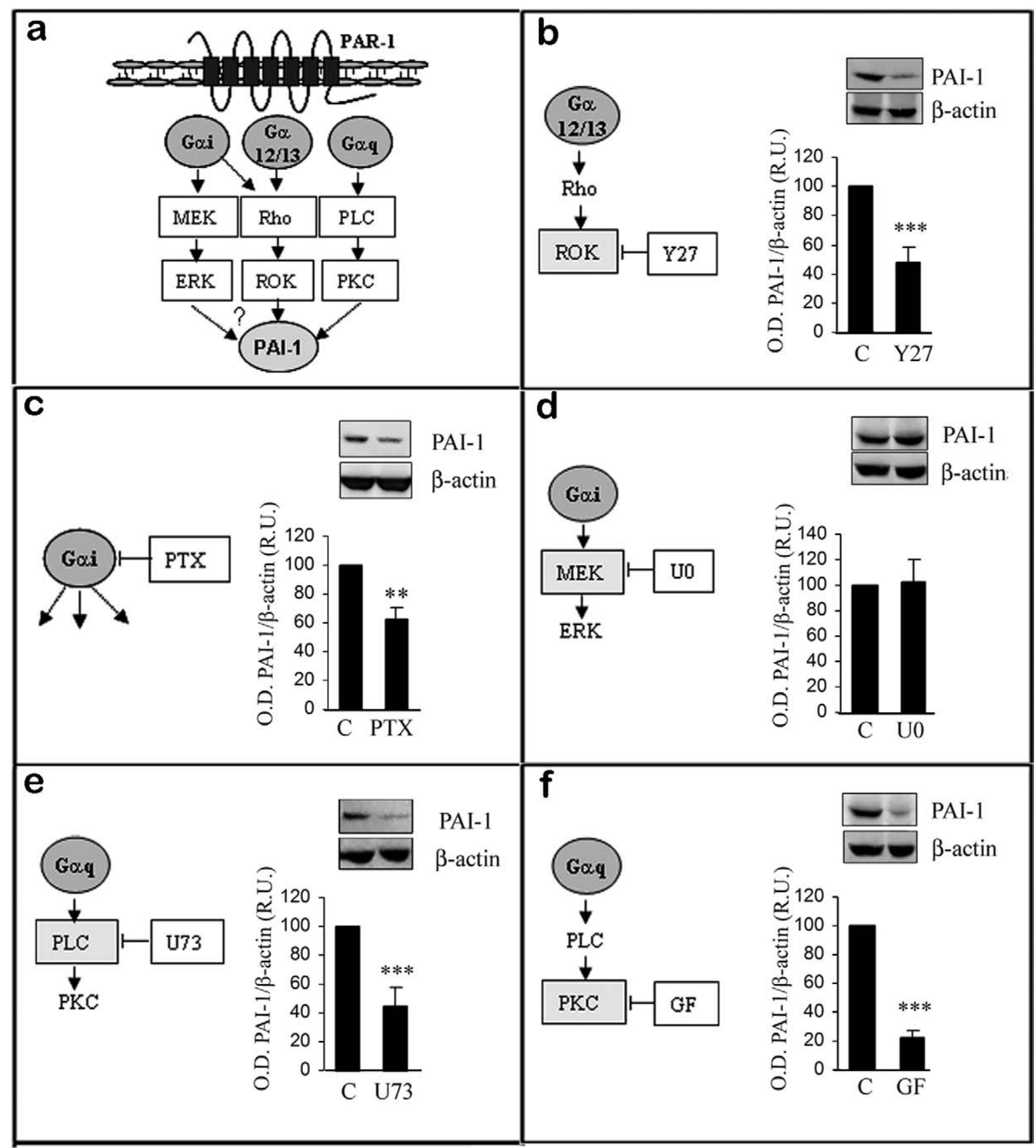

Fig. 6. Effect of different signaling inhibitors on PAI-1 expression by hTL4-OEG. (a) Main signaling pathways that couple to the PAR-1 receptor. The hTL4 cells were maintained in the presence or absence of Y27623 $(10 \mu \mathrm{M}$; Y27, b), PTX (100 ng/mL; c), U0126 (10 $\mu \mathrm{M}$; U0, d), U73122 $(10 \mu \mathrm{M}$; U73, e), or GF109203X $(10 \mu \mathrm{M}$; GF, f) for $24 \mathrm{~h}$, after

PAR-1 (Fig. 5c), and this effect could be abrogated in the presence of the PAR-1 antagonist, SCH-79797 (Fig. 5c).

Additionally, to verify that the concomitant reduction of PAI-1 was also responsible for the impairment of axonal regeneration of RGCs in the co-cultures with PAR-1 silencing OEG (hTL4 and primary OEG), we added to these co-cultures recombinant PAI-1, and we found that this was able to recover the axonal regeneration of RGC which PAI-1 expression was examined in Western blots using an antibody against $\beta$-actin as a loading control. Histograms show the densitometric quantification of PAI-1 normalized to $\beta$-actin and referred to control untreated cells values $(100 \%)$. Means \pm SEM of three experiments (*: $P<0.05$; **: $P<0.01$; ***: $P<0.005$, Student's $t$ test).

provoked by the silencing of PAR-1, confirming the role of PAI-1 as downstream effector of PAR-1 (Fig. 5d).

\section{PAR-1 Signaling Is Implicated in PAI-1 Expression and in Axonal Regeneration}

PAR-1 activates different G protein and signal transduction pathways in cells (scheme in Fig. 6a) and thus, 


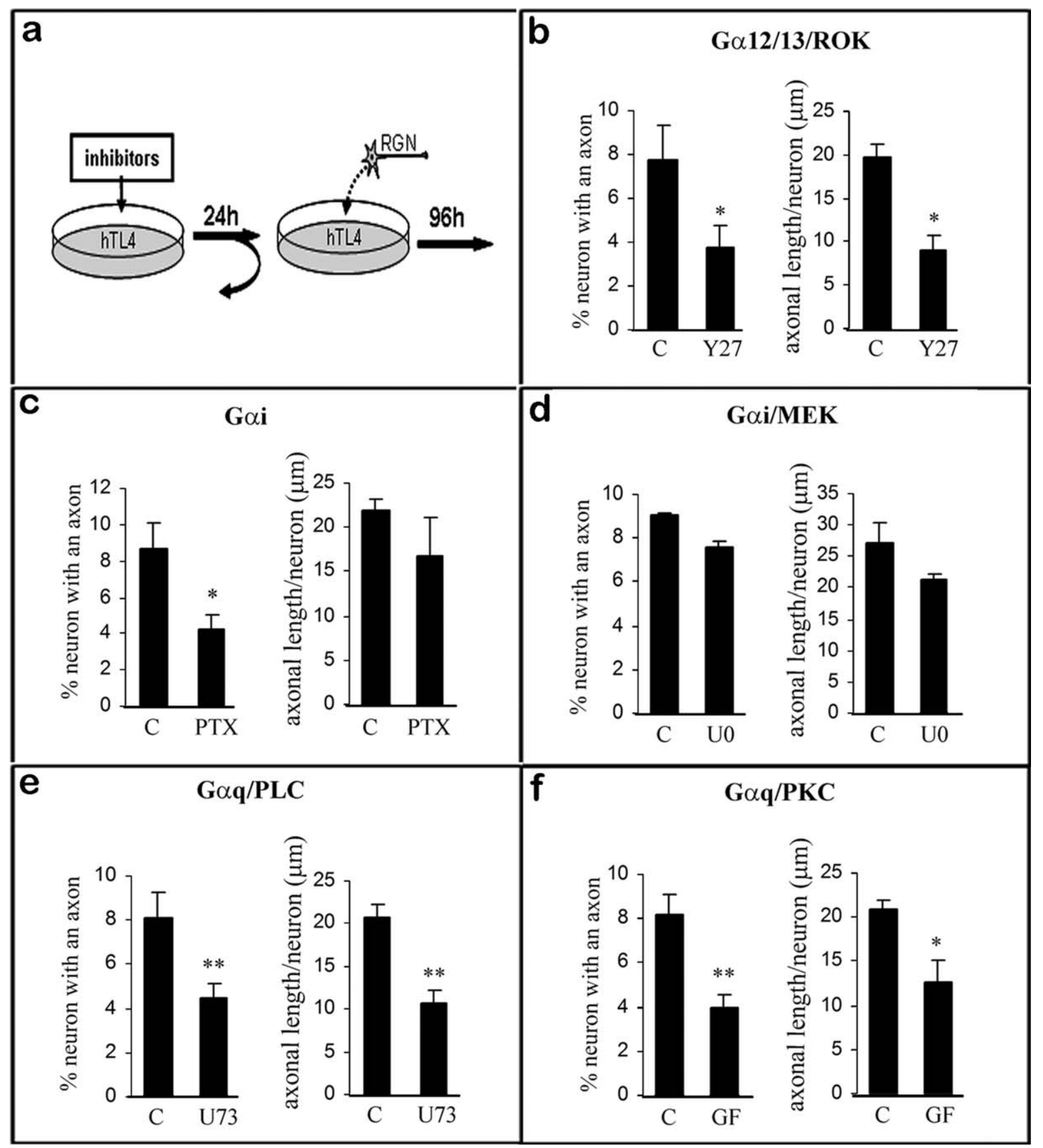

Fig. 7. Effect of the different signaling inhibitors on axonal regeneration induced by hTL4-OEG. Quantification of percentage of neurons with an axon and the mean axonal length per neuron ([axonal length/ neuron $(\mu \mathrm{m})$ ] defined as in Fig. 1) in RGCs cultured on untreated hTL4-OEG or those previously exposed $24 \mathrm{~h}$ to the following inhibitors

we set out to determine the mechanism by which PAR-1 could augment PAI-1 expression. We first investigated whether PAI-1 expression was controlled through $\mathrm{G}_{12 / 13}$, the $\alpha$ subunit of which mediates the signals from PAR-1 through Rho GTPase to Rho associated kinase (ROCK) (scheme in Fig. 6b). Incubation of hTL4 cells ( $24 \mathrm{~h}$ ) with Y27632, the specific inhibitor of ROCK, also significantly decreased PAI-1 expression (Fig. 6b) and the regenera- (see scheme in a): Y27632 (b), PTX (c), U0126 (d), U73122(e), or GF109203X (f) (concentrations as indicated in Fig. 6). Data are expressed as mean \pm SEM of at least three assays. (*: $P<0.05$; **: $P$ $<0.01$; ***: $P<0.005$, Student's $t$ test).

tion of axons by RGC co-cultured with hTL4 pretreated with this inhibitor (Fig. 7a,b).

We also studied the implication of $\mathrm{G} \alpha_{\mathrm{i}}$ by exposing hTL4 cells to pertussis toxin (PTX) for $24 \mathrm{~h}$, which moderately reduced PAI-1 expression (Fig. 6c). Moreover, when hTL4 cells were pretreated for $24 \mathrm{~h}$ with PTX and co-cultured with adult RGCs, the decrease in PAI-1 expression was concomitant with a decrease in the 
percentage of neurons with an axon (Fig. 7c). By contrast, the specific inhibitor of the mitogen-activated protein kinase kinase (MEK), U0126 (MAP Kinase pathway from $\mathrm{G} \alpha_{i}$, scheme in Fig. $6 \mathrm{~d}$ ) did not decrease either the expression of PAI-1 or OEG-dependent axonal regeneration in RGCs (Figs. 6d and 7d).

Finally, we tested the possible involvement of $\mathrm{G} \alpha_{\mathrm{q}}$ in PAI-1 expression and in axonal regeneration. Downstream of PAR-1, G $\alpha_{q}$ partially signals through PLC and further downstream, through PKC (schemes in Fig. $6 e, f)$. We tested whether this pathway might be involved in the effects of PAR-1 on axon regeneration using U73122 and GF109203X, specific inhibitors of PLC and $\mathrm{PKC}$, respectively. We found that not only was PAI-1 expression severely diminished in hTL4 cells incubated for $24 \mathrm{~h}$ with these inhibitors (Fig. 6e,f), but axonal regeneration was also inhibited in RGCs that were co-cultured with hTL4 pretreated with both these inhibitors, both in terms of the proportion of neurons with an axon and of the mean axonal length per neuron (Fig. 7e,f).

To test if the increase of PAI-1 is dependent on G-protein pathways downstream of PAR-1 activation, we determined if these inhibitors were also able to abrogate thrombin-induced PAI-1 expression. We found that PTX, GF109203X, and Y27632 indeed prevented PAI-1 upregulation mediated by thrombin activation of PAR-1 (Supp. Info. Fig. 2a).

In further agreement with the role of PAI-1 as the downstream effector of PAR-1 activation, we also observed that recombinant PAI-1 was able to recover the axonal regeneration of $\mathrm{RGC}$ after its reduction provoked by Y27632 and GF109203X pretreatment of the OEG monolayer (Supp. Info. Fig. 2b).

\section{Thrombomodulin Acts as an Inhibitory Molecule for Adult Axonal Regeneration}

Using a lentivector that expressed shRNA directed against TM (shTM, Fig. 8a) and confirming its efficiency by Western blot (Fig. 8b), we observed that silencing this protein in hTL4 produced a modest but significant increase in the percentage of neurons with an axon in RGCs in co-culture, and that the mean axonal length per neuron increased by $40 \%$ (Fig. 8c). In parallel, we also detected an increase of $\sim 70 \%$ in PAI-1 expression in TM-silenced hTL4 cells (Fig. 8d). Thus, TM seems to modulate this axonal regeneration system, probably by coupling to thrombin in co-cultures and impeding the signaling through PAR-1 in OEG.

\section{DISCUSSION}

OEG facilitate axon regeneration in damaged neurons, and this effect may occur at two levels: through a direct interaction between OEG and neurons or through secreted factors. We have focused here on one such secreted factor that facilitates axonal recovery in cultured RGCs, PAI-1. We found that PAR-1 and its a

TM CDNA

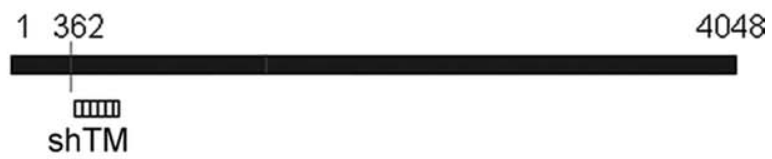

b
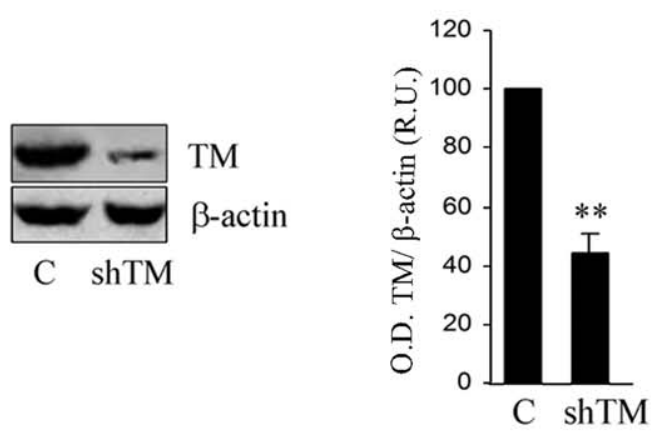

C
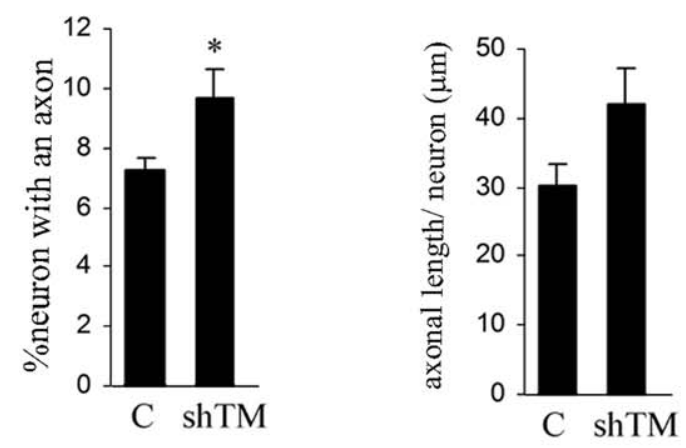

d
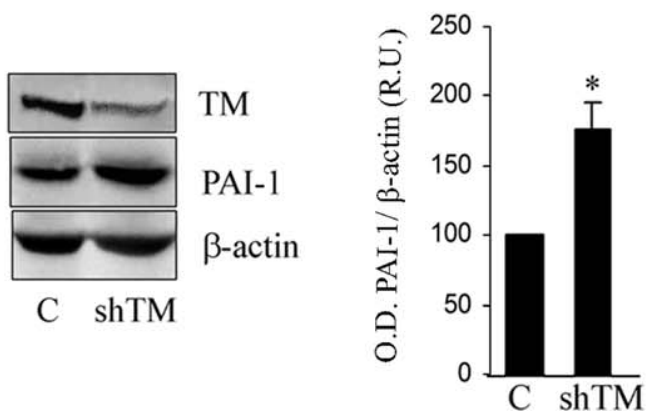

Fig. 8. Role of thrombomodulin in inhibition of adult axon regeneration. Lentivector that expressed a shRNA directed against TM (shTM, scheme a) was used to diminish TM expression in hTL4 OEG cells three days prior to adding neurons to the co-culture. After $96 \mathrm{~h}, \mathrm{TM}$ expression was analyzed by Western blot (b). The intensity of the protein band in the blots was determined by densitometry, and the levels of TM were normalized to $\beta$-actin. (c) RGC regeneration on TM-silenced OEGs (shTM) or on unsilenced OEGs (nontarget ShRNA, C), quantifying the percentage of neurons with an axon and the mean axonal length per neuron ([axonal length/neuron $(\mu \mathrm{m})]$ defined as in Fig. 1). (d) Analysis of PAI-1 and TM expression in Western blots of TMsilenced hTL4 cells was carried out using monoclonal antibodies against these proteins. An antibody against $\beta$-actin was employed as a loading control, and relative optical density values are expressed as percentage of those in control cells. Results are expressed as mean \pm SEM of three experiments. (*: $P<0.05$; **: $P<0.01$; ***: $P<0.005$, Student's $t$ test). Note increased PAI-1 expression in TM-silenced hTL4 cells. 


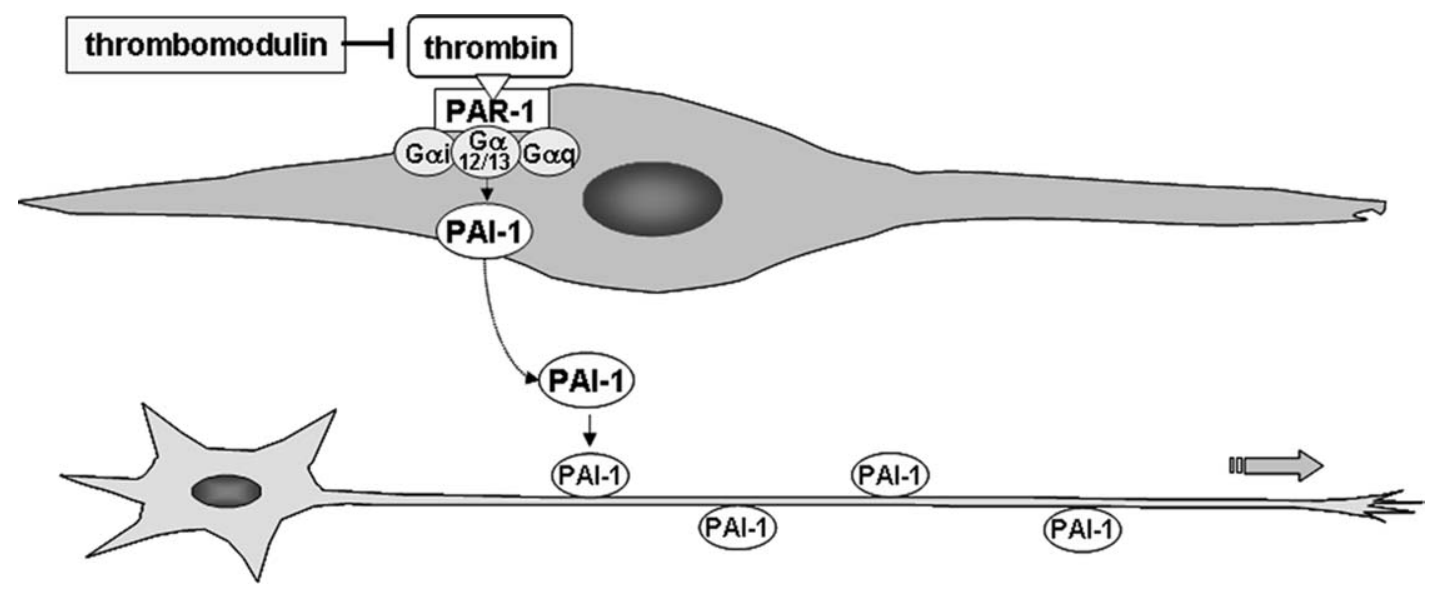

Fig. 9. Possible mechanism by which OEG stimulate axonal regeneration. The expression of PAI-1 in OEG is regulated by activation of PAR-1 and subsequent signaling through its downstream G proteins. Ultimately, glial PAI-1 acts on adult neurons stimulating axonal regrowth. Thrombin, the main activator of PAR-1, can be sequestered

downstream mediator PAI-1 are implicated in OEG-dependent axon regeneration of adult CNS neurons (RGCs) in our co-culture model. Presilencing PAR-1 and PAI-1 in hTL4 cells impedes axon regeneration in co-cultured adult RGC, without affecting to their adhesion and/or survival (as judged by the number of counted neurons/ field). Moreover, the increase of PAI-1 in OEG is due to the activation of PAR-1, since PAR- 1 silencing provokes a significant decrease in PAI-1 expression, an effect not observed on PAR-1 expression when PAI-1 is silenced.

The main activating protease of PAR-1 is thrombin. Both prothrombin and thrombin have been detected in the CNS (Citron et al., 2000; Deschepper et al., 1991), suggesting that the Thrombin/PAR system may be active in the CNS. Different actions of thrombin have been observed in vitro in glia and neurons, depending on its concentration. Thus, in the picomolar range, astrocytes suffer morphologic changes on exposure to thrombin, reversing stellation (Pindon et al., 1998; Suidan et al., 1997), while at nanomolar concentrations thrombin induces the proliferation of astrocytes (Grabham and Cunningham, 1995). At picomolar concentrations, thrombin appears to protect neurons and astrocytes from different death stimuli, while at higher concentration, it causes neuronal and astrocyte death (Vaughan et al., 1995). In addition, thrombin also appears to produce neurite retraction in neurons (Suidan et al., 1992), and PAR-1 and 2 mediate neurite retraction in olfactory sensory neurons (Olianas et al., 2007). Therefore, the effect of this protease in neuronal cells depends on its concentration and could impair neuroregeneration. However, we describe the consequences of activation of thrombin system in OEG cells and how this contributes to their regenerative capacity.

An increase in prothrombin expression has been described soon after spinal cord injury in astrocytic, microglial, and neuronal population (Citron et al., 2000), and a consequence of the increase in thrombin could be the induction of axon retraction and/or neuron degenera- by TM preventing its binding to PAR-1 and thus causing a concomitant reduction in PAI-1. Consequently, TM expression and the control of PAI-1 amount play an important role in the axonal regenerative function of this cell type.

tion following activation of neuronal PAR-1 (Suidan et al., 1992).

However, signaling through PAR-1 may result in axonal regeneration in our mixed glia-neuron regenerative cultures through two different ways. First, in the presence of OEG, competition between OEG and neuronal PAR-1 receptors for thrombin may occur. Therefore, OEG transplanted in the injured spinal cord would reduce the amount of toxic thrombin available to neurons. Second, thrombin is also able to activate PAR-1 expression in OEG, leading to the secretion of PAI-1 that can in turn drive axonal regeneration. This process seems to be more efficient if the amount of TM, a protein that complexes to thrombin, produced by the OEG decreases (see scheme in Fig. 9). In addition, it has been reported that thrombin increases the level of PAI-1 in other cellular systems, including smooth muscle cells, endothelial cells, epithelial cells, and lung fibroblasts (Dichek and Quertermous, 1989; Hayakawa et al., 1995; Noda-Heiny et al., 1993). Thus, the present work demonstrates that the stimulation of PAI-1 by thrombin also occurs in nervous system cells, and this mechanism may have a role in OEG-dependent neuroregeneration.

TM is an allosteric modulator of thrombin that inhibits fibrinolytic thrombin activity (Esmon, 1987), mediates Protein $\mathrm{C}$ activation by thrombin, and importantly, attenuates thrombin effects through PAR-1 (Bhattacharya and Cohen, 2000). Recent studies support the expression and activity of TM in the human and murine CNS (Pindon et al., 1997; Wong et al., 1991). In our system, TM expression increased in a nonregenerative population of rat OEG (Pastrana et al., 2006), probably at least in part due to its coupling to thrombin producing a decrease in PAR-1 signaling. Accordingly, we found that silencing TM increases the expression of PAI-1, which was paralleled by an increase of OEG-dependent axon regeneration. Consequently, the control of TM in the injured and regenerating CNS may also be important. 
We studied the PAR-1 signaling that drives PAI-1 expression in OEG-dependent axonal regeneration in more detail. PAR- 1 can couple to $\mathrm{G} \alpha_{\mathrm{i}}, \mathrm{G} \alpha_{\mathrm{q}}$, and $\mathrm{G} \alpha_{12 / 13}$, (Hung et al., 1992; Offermanns et al., 1994), and these $\mathrm{G}$ proteins stimulate different signaling pathways. $\mathrm{G} \alpha_{\mathrm{i}}$ inhibits adenylate cyclase and activates some MAPKs like extracellular signal-regulated kinases 1/2 (ERK1/2), while $\mathrm{G \alpha}_{12 / 13}$ activates the small $\mathrm{G}$ protein Rho and the downstream Rho kinase (Suidan et al., 1997). Finally, $\mathrm{G \alpha}_{\mathrm{q}}$ stimulates phospholipase C, which increases the intracellular calcium concentration and activates PKC (Pindon et al., 1998; Wang et al., 2002), as well as triggering the activation of the MAPKs like ERK1/2, c-jun N-terminal kinase (JNK), and p38MAPK (Suo et al., 2002; Wang et al., 2007; Xi et al., 2001). Our results support the implication of the signaling pathways downstream of three $G$ proteins in driving PAI-1 expression from PAR-1 and in OEG-dependent regeneration: $\mathrm{G} \alpha_{\mathrm{i}}, \mathrm{G}_{\alpha_{12 / 13}}$, and $\mathrm{G} \alpha_{\mathrm{q}}$. After removal of the inhibitors of these pathways by washing OEG monolayers, we observed continued PAI-1 downregulation for at least $16 \mathrm{~h}$ (data not shown). Thus, treatment by inhibitors results in low PAI-1 expression in OEGs during the first hours after neuron plating, the critical period for initiation of neurite outgrowth and for the first stages in the establishment of axonal/dendritic polarity. Together with the rest of our results, these data provide an explanation of how drug effects on PAI-1 expression can influence axonal regeneration of RGCs. Additionally, we did not find differences between treatments in neuronal adhesion/survival as judged by the number of counted neurons/field in our co-culture experiments.

We have demonstrated the role of PLC and PKC in OEG neurogenerative capacity promoted by PAI-1 upregulation. These effects are probably downstream of PAR- $1 / G \alpha_{q}$ signaling. Additionally, these effects are mediated through Rho/ROCK signaling, downstream of $\mathrm{G} \alpha_{12 / 13}$. While $\mathrm{G} \alpha_{\mathrm{i}}$ seems to moderately regulate PAI- 1 expression, its downstream MEK/ERK signaling does not seem to be implicated in this process. Although the Rho/ROCK pathway is mainly coupled to $\mathrm{G} \alpha_{12 / 13}$, there is some evidence that Rho/ROCK activity could be modulated through $\mathrm{G}_{\mathrm{i}_{\mathrm{i}}}$-mediated signaling (Betuing et al., 1998). Thus, in agreement with our observation that ROCK is implicated in the regulation of the expression of PAI-1, this protein could be the link between $G \alpha_{i}$ and PAI-1 expression.

All these signaling cascades are involved in different processes in distinct tissues, including the CNS, although PAR-1 is best known for its role in coagulation (Macfarlane et al., 2001). PAR-1 is expressed extensively in the brain, where its presence is more or less pronounced depending on the region (Striggow et al., 2001). At the cellular level, PAR-1 is expressed in neurons, astrocytes, microglia, and OEGs (Moller et al., 2000; Wang et al., 2002), and it has been demonstrated that picomolar concentrations of thrombin reverse astrocyte stellation through the activation of PKC and Rho (Pindon et al., 1998; Suidan et al., 1997).
PAI-1 would ultimately be responsible for mediating axonal regeneration in this system. Studies indicate that PAI-1 is produced by both neuronal and glial cells in the brain (Presta et al., 1990). It has been postulated that enzymatic digestion of the extracellular matrix by proteases may play a role in migration and in the advancement of neuronal processes during brain development and axonal regeneration (Pastrana et al., 2006; Pittman et al., 1989). The inhibition of protease activity has been correlated with the stimulation of neurite outgrowth (Diaz-Nido et al., 1991), and it has been suggested that the PA/PAI-1 system might be involved in this effect (Leprince et al., 1991). Indeed, inhibition of PA increases neurite outgrowth in sympathetic neurons and PC12 cells (Pittman et al., 1989), and the stimulation of PAI activity by NGF in PC12 cells is associated with the formation of large neurites, while PA activity in response to dibutiryl adenosine $3^{\prime}, 5^{\prime}$-cyclic monophosphate (dbcAMP) produces short neurites. In this paradigm, the combined stimulation with both dbcAMP and NGF gives way to the production of a tPA-PAI complex and the extension of very large neurites (Leprince et al., 1991).

In this study, we have shown that human OEG, represented by the hTL4 immortalized line (Lim et al., 2010), express PAI-1 mainly as a result of PAR-1 activation and signaling mostly via $\mathrm{G}_{12 / 13}$ and $\mathrm{G} \alpha_{\mathrm{q}}$ (PLC and $\mathrm{PKC}$ ), thus mediating axonal regeneration in adult CNS neurons. Investigation of the cellular pattern and the activity of this thrombin-PAR-1 signaling system in a lesioned CNS environment is therefore important to further understanding of the neurodegenerative processes underlying injury. In addition, in the light of our findings, this thrombin system may play an important role in axonal regeneration. Our data using an in vitro model of adult CNS axonal regeneration (RGC co-culture) indicate that PAI-1 effects, as a secreted factor, account for a significant part of OEG-mediated neuroregeneration.

These OEG properties are due to a combination of several factors (see for review (Moreno-Flores and Avila, 2006). In our present study, we have dissected one of the mechanisms of OEG-dependent regeneration by demonstrating for first time that human OEG express PAI-1 due to PAR-1 activation and signaling mainly through $\mathrm{G} \alpha_{12 / 13}$ and $\mathrm{G} \alpha_{\mathrm{q}}$ (PLC and PKC), to result in axonal regeneration in adult CNS neurons. In the light of our findings, the thrombin system forms an important part of the ensemble of OEG mechanisms contributing to axonal regeneration. The complete elucidation of the pathways implicated in OEG-dependent axonal regeneration promoted by this thrombin-PAR-1 signaling system in the context of a lesioned CNS environment will merit further research.

\section{ACKNOWLEDGMENTS}

D.S. was supported by contracts from the Fundación M. Botín and CIBERNED; E.P. was the recipient of an FPI fellowship; M.J.M. was supported by a contract from Noscira; F.L. was the recipient of an I3 incorporation 
contract from the Spanish Ministry; and M.T.M. was supported by contracts from the C.S.I.C. (I3P) and the Fundación M. Botín.

\section{REFERENCES}

Barnett SC, Riddell JS. 2007. Olfactory ensheathing cell transplantation as a strategy for spinal cord repair-what can it achieve? Nat Clin Pract Neurol 3:152-161.

Betuing S, Daviaud D, Pages C, Bonnard E, Valet P, Lafontan M, Saulnier-Blache JS. 1998. Gbeta gamma-independent coupling of alpha2adrenergic receptor to $\mathrm{p} 21(\mathrm{rhoA})$ in preadipocytes. J Biol Chem 273:15804-15810.

Bhattacharya A, Cohen ML. 2000. Vascular contraction and relaxation to thrombin and trypsin: Thrombomodulin preferentially attenuates thrombin-induced contraction. J Pharmacol Exp Ther 295:284-290.

Cavanaugh KP, Gurwitz D, Cunningham DD, Bradshaw RA. 1990. Reciprocal modulation of astrocyte stellation by thrombin and protease nexin-1. J Neurochem 54:1735-1743.

Chuah MI, Choi-Lundberg D, Weston S, Vincent AJ, Chung RS, Vickers JC, West AK. 2004. Olfactory ensheathing cells promote collateral axonal branching in the injured adult rat spinal cord. Exp Neurol 185:15-25.

Citron BA, Smirnova IV, Arnold PM, Festoff BW. 2000. Upregulation of neurotoxic serine proteases, prothrombin, and protease-activated receptor 1 early after spinal cord injury. J Neurotrauma 17:1191-1203.

Deschepper CF, Bigornia V, Berens ME, Lapointe MC. 1991. Production of thrombin and antithrombin III by brain and astroglial cell cultures. Brain Res Mol Brain Res 11:355-358.

Diaz-Nido J, Armas-Portela R, Avila J. 1991. Addition of protease inhibitors to culture medium of neuroblastoma cells induces both neurite outgrowth and phosphorylation of microtubule-associated protein MAP-1B. J Cell Sci 98(Pt 3):409-414.

Dichek D, Quertermous T. 1989. Thrombin regulation of mRNA levels of tissue plasminogen activator and plasminogen activator inhibitor-1 in cultured human umbilical vein endothelial cells. Blood $74: 222-228$

Esmon CT. 1987. The regulation of natural anticoagulant pathways. Science 235:1348-1352.

Garcia-Escudero V, Garcia-Gomez A, Gargini R, Martin-Bermejo MJ, Langa E, de Yebenes JG, Delicado A, Avila J, Moreno-Flores MT, Lim F. 2010. Prevention of senescence progression in reversibly immortalized human ensheathing glia permits their survival after deimmortalization. Mol Ther 18:394-403.

Garcia-Escudero V, Gargini R, Gallego-Hernandez MT, Garcia-Gomez A, Martin-Bermejo MJ, Simon D, Delicado A, Moreno-Flores MT, Avila J, Lim F. 2011. A neuroregenerative human ensheathing glia cell line with conditional rapid growth. Cell Transplant 20:153-166.

Grabham P, Cunningham DD. 1995. Thrombin receptor activation stimulates astrocyte proliferation and reversal of stellation by distinct pathways: Involvement of tyrosine phosphorylation. J Neurochem 64:583-591.

Hackett SF, Campochiaro PA. 1993. Modulation of plasminogen activator inhibitor-1 and urokinase in retinal pigmented epithelial cells. Invest Ophthalmol Vis Sci 34:2055-2061.

Hayakawa Y, Tazawa S, Ishikawa T, Niiya K, Sakuragawa N. 1995. Transcriptional regulation of tissue- and urokinase-type plasminogen activator genes by thrombin in human fetal lung fibroblasts. Thromb Haemost 74:704-710.

Hung DT, Wong YH, Vu TK, Coughlin SR. 1992. The cloned platelet thrombin receptor couples to at least two distinct effectors to stimulate phosphoinositide hydrolysis and inhibit adenylyl cyclase. J Biol Chem 267:20831-20834

Imaizumi T, Lankford KL, Waxman SG, Greer CA, Kocsis JD. 1998. Transplanted olfactory ensheathing cells remyelinate and enhance axonal conduction in the demyelinated dorsal columns of the rat spinal cord. J Neurosci 18:6176-6185.

Laemmli UK. 1970. Cleavage of structural proteins during the assembly of the head of bacteriophage T4. Nature 227:680-685.

Leprince P, Rogister B, Delree P, Rigo JM, Andre B, Moonen G. 1991. Modulation of proteolytic activity during neuritogenesis in the PC12 nerve cell: Differential control of plasminogen activator and plasminogen activator inhibitor activities by nerve growth factor and dibutyryl-cyclic AMP. J Neurochem 57:665-674.

Li Y, Field PM, Raisman G. 1997. Repair of adult rat corticospinal tract by transplants of olfactory ensheathing cells. Science 277:20002002.

Lim F, Martin-Bermejo MJ, Garcia-Escudero V, Gallego-Hernandez MT, Garcia-Gomez A, Rabano A, Diaz-Nido J, Avila J, Moreno-Flores MT.
2010. Reversibly immortalized human olfactory ensheathing glia from an elderly donor maintain neuroregenerative capacity. Glia 58:546-558.

Macfarlane SR, Seatter MJ, Kanke T, Hunter GD, Plevin R. 2001. Proteinase-activated receptors. Pharmacol Rev 53:245-282.

Moller T, Hanisch UK, Ransom BR. 2000. Thrombin-induced activation of cultured rodent microglia. J Neurochem 75:1539-1547.

Monard D, Niday E, Limat A, Solomon F. 1983. Inhibition of protease activity can lead to neurite extension in neuroblastoma cells. Prog Brain Res 58:359-364.

Moreno-Flores MT, Avila J. 2006. The quest to repair the damaged spinal cord. Recent Pat CNS Drug Discov 1:55-63.

Moreno-Flores MT, Bradbury EJ, Martin-Bermejo MJ, Agudo M, Lim F Pastrana E, Avila J, Diaz-Nido J, McMahon SB, Wandosell F. 2006. A clonal cell line from immortalized olfactory ensheathing glia promotes functional recovery in the injured spinal cord. Mol Ther 13:598-608.

Moreno-Flores MT, Diaz-Nido J, Wandosell F, Avila J. 2002. Olfactory ensheathing glia: Drivers of axonal regeneration in the central nervous system?. J Biomed Biotechnol 2:37-43.

Moreno-Flores MT, Lim F, Martin-Bermejo MJ, Diaz-Nido J, Avila J, Wandosell F. 2003a. High level of amyloid precursor protein expression in neurite-promoting olfactory ensheathing glia (OEG) and OEG-derived cell lines. J Neurosci Res 71:871-881.

Moreno-Flores MT, Lim F, Martin-Bermejo MJ, Diaz-Nido J, Avila J, Wandosell F. 2003b. Immortalized olfactory ensheathing glia promote axonal regeneration of rat retinal ganglion neurons. J Neurochem 85:861-871.

Noda-Heiny H, Fujii S, Sobel BE. 1993. Induction of vascular smooth muscle cell expression of plasminogen activator inhibitor-1 by thrombin. Circ Res 72:36-43.

Offermanns S, Laugwitz KL, Spicher K, Schultz G. 1994. G proteins of the G12 family are activated via thromboxane A2 and thrombin receptors in human platelets. Proc Natl Acad Sci U S A 91:504-508.

Olianas MC, Dedoni S, Onali P. 2007. Proteinase-activated receptors 1 and 2 in rat olfactory system: Layer-specific regulation of multiple signaling pathways in the main olfactory bulb and induction of neurite retraction in olfactory sensory neurons. Neuroscience 146:12891301.

Pastrana E, Moreno-Flores MT, Avila J, Wandosell F, Minichiello L, Diaz-Nido J. 2007. BDNF production by olfactory ensheathing cells contributes to axonal regeneration of cultured adult CNS neurons. Neurochem Int 50:491-498.

Pastrana E, Moreno-Flores MT, Gurzov EN, Avila J, Wandosell F, DiazNido J. 2006. Genes associated with adult axon regeneration promoted by olfactory ensheathing cells: A new role for matrix metalloproteinase 2. J Neurosci 26:5347-5359.

Perraud F, Besnard F, Sensenbrenner M, Labourdette G. 1987. Thrombin is a potent mitogen for rat astroblasts but not for oligodendroblasts and neuroblasts in primary culture. Int J Dev Neurosci 5:181-188.

Pindon A, Festoff BW, Hantai D. 1998. Thrombin-induced reversal of astrocyte stellation is mediated by activation of protein kinase $\mathrm{C}$ beta-1. Eur J Biochem 255:766-774.

Pindon A, Hantai D, Jandrot-Perrus M, Festoff BW. 1997. Novel expression and localization of active thrombomodulin on the surface of mouse brain astrocytes. Glia 19:259-268.

Pittman RN, Ivins JK, Buettner HM. 1989. Neuronal plasminogen activators: Cell surface binding sites and involvement in neurite outgrowth. J Neurosci 9:4269-4286.

Presta M, Ennas MG, Torelli S, Ragnotti G, Gremo F. 1990. Synthesis of urokinase-type plasminogen activator and of type- 1 plasminogen activator inhibitor in neuronal cultures of human fetal brain: Stimulation by phorbol ester. J Neurochem 55:1647-1654.

Raisman G, Li Y. 2007. Repair of neural pathways by olfactory ensheathing cells. Nat Rev Neurosci 8:312-319.

Ramer LM, Au E, Richter MW, Liu J, Tetzlaff W, Roskams AJ. 2004. Peripheral olfactory ensheathing cells reduce scar and cavity formation and promote regeneration after spinal cord injury. J Comp Neurol 473:1-15.

Ramon-Cueto A, Cordero MI, Santos-Benito FF, Avila J. 2000. Functional recovery of paraplegic rats and motor axon regeneration in their spinal cords by olfactory ensheathing glia. Neuron 25:425-435.

Ramón y Cajal S. 1928. Degeneration and regeneration of the nervous system. London, Oxford Univ. Press (translated by May RM).

Richter MW, Roskams AJ. 2008. Olfactory ensheathing cell transplantation following spinal cord injury: Hype or hope? Exp Neurol 209:353367.

Salinero O, Moreno-Flores MT, Ceballos ML, Wandosell F. 1997. betaAmyloid peptide induced cytoskeletal reorganization in cultured astrocytes. J Neurosci Res 47:216-223.

Sanchez Martin C, Diaz-Nido J, Avila J. 1998. Regulation of a site-specific phosphorylation of the microtubule-associated protein 2 during the development of cultured neurons. Neuroscience 87:861-870. 
Sasaki M, Hains BC, Lankford KL, Waxman SG, Kocsis JD. 2006. Protection of corticospinal tract neurons after dorsal spinal cord transection and engraftment of olfactory ensheathing cells. Glia 53:352-359.

Sonigra RJ, Brighton PC, Jacoby J, Hall S, Wigley CB. 1999. Adult rat olfactory nerve ensheathing cells are effective promoters of adult central nervous system neurite outgrowth in coculture. Glia 25:256-269.

Sternberger LA, Sternberger NH. 1983. Monoclonal antibodies distinguish phosphorylated and nonphosphorylated forms of neurofilaments in situ. Proc Natl Acad Sci U S A 80:6126-6130.

Striggow F, Riek-Burchardt M, Kiesel A, Schmidt W, Henrich-Noack P, Breder J, Krug M, Reymann KG, Reiser G. 2001. Four different types of protease-activated receptors are widely expressed in the brain and are up-regulated in hippocampus by severe ischemia. Eur J Neurosci 14:595-608.

Suidan HS, Nobes CD, Hall A, Monard D. 1997. Astrocyte spreading in response to thrombin and lysophosphatidic acid is dependent on the Rho GTPase. Glia 21:244-252.

Suidan HS, Stone SR, Hemmings BA, Monard D. 1992. Thrombin causes neurite retraction in neuronal cells through activation of cell surface receptors. Neuron 8:363-375.

Sumi Y, Dent MA, Owen DE, Seeley PJ, Morris RJ. 1992. The expression of tissue and urokinase-type plasminogen activators in neural development suggests different modes of proteolytic involvement in neuronal growth. Development 116:625-637.

Suo Z, Wu M, Ameenuddin S, Anderson HE, Zoloty JE, Citron BA, Andrade-Gordon P, Festoff BW. 2002. Participation of protease-activated receptor-1 in thrombin-induced microglial activation. J Neurochem 80:655-666.

Thuret S, Moon LD, Gage FH. 2006. Therapeutic interventions after spinal cord injury. Nat Rev Neurosci 7:628-643.

Ulloa L, Avila J, Diaz-Nido J. 1993a. Heterogeneity in the phosphorylation of microtubule-associated protein MAP1B during rat brain development. J Neurochem 61:961-972.
Ulloa L, Diaz-Nido J, Avila J. 1993b. Depletion of casein kinase II by antisense oligonucleotide prevents neuritogenesis in neuroblastoma cells. EMBO J 12:1633-1640.

Vassalli JD, Sappino AP, Belin D. 1991. The plasminogen activator/ plasmin system. J Clin Invest 88:1067-1072.

Vaughan PJ, Pike CJ, Cotman CW, Cunningham DD. 1995. Thrombin receptor activation protects neurons and astrocytes from cell death produced by environmental insults. J Neurosci 15(7 Pt 2):5389-5401.

Vu TK, Hung DT, Wheaton VI, Coughlin SR. 1991. Molecular cloning of a functional thrombin receptor reveals a novel proteolytic mechanism of receptor activation. Cell 64:1057-1068.

Wang H, Ubl JJ, Reiser G. 2002. Four subtypes of protease-activated receptors, co-expressed in rat astrocytes, evoke different physiological signaling. Glia 37:53-63.

Wang Y, Luo W, Reiser G. 2007. Proteinase-activated receptor-1 and -2 induce the release of chemokine GRO/CINC-1 from rat astrocytes via differential activation of JNK isoforms, evoking multiple protective pathways in brain. Biochem J 401:65-78.

Wang Y, Luo W, Wartmann T, Halangk W, Sahin-Toth M, Reiser G. 2006. Mesotrypsin, a brain trypsin, activates selectively proteinaseactivated receptor-1, but not proteinase-activated receptor-2, in rat astrocytes. J Neurochem 99:759-769.

Wigley CB, Berry M. 1988. Regeneration of adult rat retinal ganglion cell processes in monolayer culture: Comparisons between cultures of adult and neonatal neurons. Brain Res 470:85-98.

Wong VL, Hofman FM, Ishii H, Fisher M. 1991. Regional distribution of thrombomodulin in human brain. Brain Res 556:1-5.

Xi G, Hua Y, Keep RF, Duong HK, Hoff JT. 2001. Activation of p44/42 mitogen activated protein kinases in thrombin-induced brain tolerance. Brain Res 895:153-159.

Zurn AD, Nick H, Monard D. 1988. A glia-derived nexin promotes neurite outgrowth in cultured chick sympathetic neurons. Dev Neurosci 10:17-24. 